\title{
NEW PROPOSED FORMULA FOR R.C. COLUMN SLENDERNESS RATIO LINKED WITH CONCRETE COMPRESSIVE STRENGTH AND STRESSES ON COLUMNS
}

\author{
ABD-ELHAMED, M. K. \\ Faculty of Engineering, Al - Azhar University, Cairo, Egypt
}

\begin{abstract}
Many codes for reinforced concrete columns design adopted by various countries are in fact built upon empirical formulae. However, Egyptian code adopted slenderness limit 30 for braced columns and 23 for unbraced columns. The mentioned values in codes do not change with different variables such as concrete compressive strength and stresses on columns as well as increases in column dimensions. This paper aimed to study the influences of parameters that affected slenderness ratio such as concrete compressive strength and stresses on columns. Also, the present study aimed to find a formula for slenderness ratio linked with concrete compressive strength $\left(f_{c u}\right)$ and stresses on column $\left(\frac{p_{u}}{A}\right)$. The results of the proposed formula fit very well with ECP 203 code and showed that an increase in slenderness limits with increase compressive concrete strength as well as decrease stresses on columns. Thus, the effect of compressive concrete strength and stresses on columns should be taken into consideration in calculating the slenderness limits.
\end{abstract}

\section{INTRODUCTION:}

Slenderness effects in columns result in reduced strength, on account of the additional 'secondary' moments introduced. In the case of very slender columns, failure may occur suddenly under small loads due to instability (elastic buckling), rather than due to material failure. The Codes attempt to prevent this type of failure (due to instability) by specifying certain 'slenderness limits' in the proportioning of columns. On the other hand, not all the codes use the same parameters in their upper slenderness limit formulae. For instance, the American Concrete Institute Code ACI 318-05 [1] adopts a limit for slender columns based on the end moment ratio. On the other hand, the Egyptian Code of Practice, ECP 203 [2], adopts a fixed limit for the slenderness limit for braced and unbraced columns regardless of the end moments and the stresses on columns as well as concrete compressive strength. Not surprisingly, large differences may be obtained when applying the above code provisions. However, there are different values of the slenderness limit for braced and unbraced column conditions.

The researchers adopted in studying the most important parameters governing the behavior of slender concrete columns, such as Moment Magnified factor, axial load, first order analysis, end eccentricities, effective length factor, flexural rigidity and compressive concrete strength.

James G. Macgregor and. et al. (1970) [3] presented a proposal for revising the slender column design procedures of ACI 318-63. It was proposed that the cross sections of slender columns be proportioned for the axial load from a nominal structural analysis combined with the moment from a similar analysis multiplied by a moment magnifier factor $(\delta)$. It is a function of the ratio of the axial load to the critical load of the column, the ratio of column end moments, and the deflected shape of the column. Macgregor and. et al. focused on factors affect the slender columns such as the normal range of variables encountered in the design of building columns. Also, Macgregor and. et al. focused on the behavior of slender columns and 
major variables affecting the strength of slender braced or unbraced columns and general requirements of design method for slender columns. It was shown that the proposed procedure is more rational and more consistent than the presently used procedure. Jostein H. (2002) [4] investigated the major factors that affect the lower slenderness limit predictions such as moment gradient, end restraints, full range of axial force, reinforcement amount and sustained loading. Jostein presented a new lower slenderness limit formulation for compression member braced against side sway. The formulation was limited to member with symmetrical reinforcement and uniform cross section. The formulation is rational and may replace, or used as an alternative to existing lower limit formulations.

Mari A. R. and Jostein H. (2005) [5] presented analytical expressions of the lower slenderness limit of symmetrically rectangular columns. The limits, associated with a chosen (5 and 10\%) loss of bearing capacity compared to no slender columns, are derived based on general mechanics of concrete structures. The proposed formulae take into account the important parameters governing the behavior of slender concrete columns, such as axial load, first order end eccentricities, ratio between permanent and total load, creep coefficient, amount as well as distribution of the reinforcement and also different loading paths. The results of the proposed formulae fit with those obtained by a nonlinear and time dependent analysis model previously developed and checked.

Jostein H. (2008) [6] reviewed the local and global second-order effects (sway-modified moments). It was concluded that the end moment ratios of approximate moment magnifier expressions and slenderness limits should be expressed in terms of sway-modified end moments. Also, Jostein reviewed the ACI limits and several inconsistencies pointed out with respect to their differences. The ACI limits was compared with a summary of nonlinear analysis results. The results of comparison documented the reliability of the limit.

Ihsan A. S and et.al (2008) [7] proposed a formula to find the effect of high strength concrete in design of columns for non-sway and sway under high axial loads. The formula of ACI 318 Code has not affected by using high strength concrete in design of columns. The applying of proposed formula giving more conservative estimation of slenderness limit values than the ACI 318 Code.

Bouzid T. and Demagh K. (2010) [8] presented reinforced concrete-encased composite columns subjected to biaxial bending and axial loads. An iterative numerical procedure was presented for the strength analysis and design of short and slender reinforced concrete columns with a square cross section under biaxial bending and an axial load by using an EC2 stress-strain model. The computational procedure takes into account the nonlinear behavior of the materials and includes the second - order effects due to the additional eccentricity of the applied axial load by the Moment Magnification Method. Bouzid T. and Demagh K tested the proposed method and its formulation by comparing the results with the experimental results. The comparison showed that a fair agreement between the experimental and theoretical results. The main objectives of the present study is to find a formula of slenderness ratio linked with concrete compressive strength $\left(f_{c u}\right)$ and stresses on column $(\mathrm{Pu} / A)$.

\section{FACTORS AFFECTING COLUMN SLENDERNESS RATIOS:}

The most important factors affecting the behavior of slenderness limit predictions of braced and unbraced members are investigated. The factors considered include, second order analysis, factor of equivalent uniform moment $(\mathrm{Cm})$, Magnified factor $(\delta)$, flexural rigidity (EI) and concrete compressive strength $\left(\mathrm{F}_{\mathrm{cu}}\right)$. This study was limited to columns with pin ended supports and uniform cross section consisted of symmetrical reinforcement.

\subsection{Second order analysis:}

In a first-order analysis, the equations of equilibrium are derived by assuming that the deflections have a negligible effect on the internal forces in the members. In a second-order analysis, the equations of equilibrium consider the deformed shape of the structure instability can be investigated only via a second-order analysis. Many designers and computer programs calculate slenderness limit based on first-order analyses methods have been derived to modify 
the results of a first-order analysis to approximate the second-order effects. Most of the slenderness limit expressions provided by codes are derived assuming a certain loss of the column bearing capacity due to the second order effect.

\subsection{Factor of equivalent uniform moment $(\mathrm{Cm})$ :}

The factor $\mathrm{Cm}$ is a correction factor relating the actual moment diagram to an equivalent uniform moment diagram. In the case of column subjected to unequal end moments as shown in Fig. (1-a) is replaced with a similar column subjected to equal moments of $\mathrm{CmM}_{2}$ at both ends as shown in Fig. (1-b).

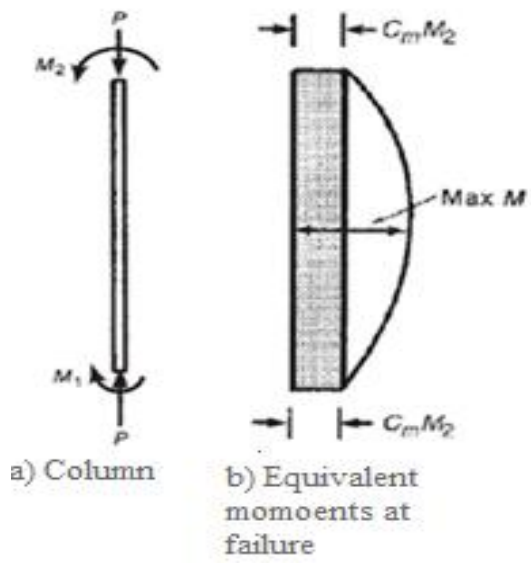

Fig. (1) Moments in columns with unequal end moments

The derivation of the moment magnifier assumes that the maximum moment is at or near midheight of the column. If the maximum moment occurs at one end of the column, design should be based on an equivalent uniform moment $\mathrm{CmM}_{2}$ that would lead to the same maximum moment when magnified [1]. The expression for the equivalent moment factor $\mathrm{Cm}$ is derived for concrete design as follows:-

$$
\mathrm{Cm}=0.60+0.40(M 1 / M 2)
$$

the above equation is according to ACI code eq. (10-16).

Where $\mathrm{M}_{1}$ is smallest end moment and $\mathrm{M}_{2}$ is the largest end moment. (M1/M2) Is positive when the end moments produce single curvature and negative when the produce double curvature. Eq. (1) applies only for braced (non-sway) column, loaded with axial loads and end moments. In all other cases, Nilson H. and at al. (2010) [9] suggested the variation of $\mathrm{Cm}$ with $(M 1 / M 2)$ as shown in fig. (2). The value of $\mathrm{Cm}=1$ in case of unbraced (side sway) frames and $\mathrm{Cm}=(0.40$ to 1$)$ according to the values and magnitude of $(M 1 / M 2)$ for braced (non-sway).

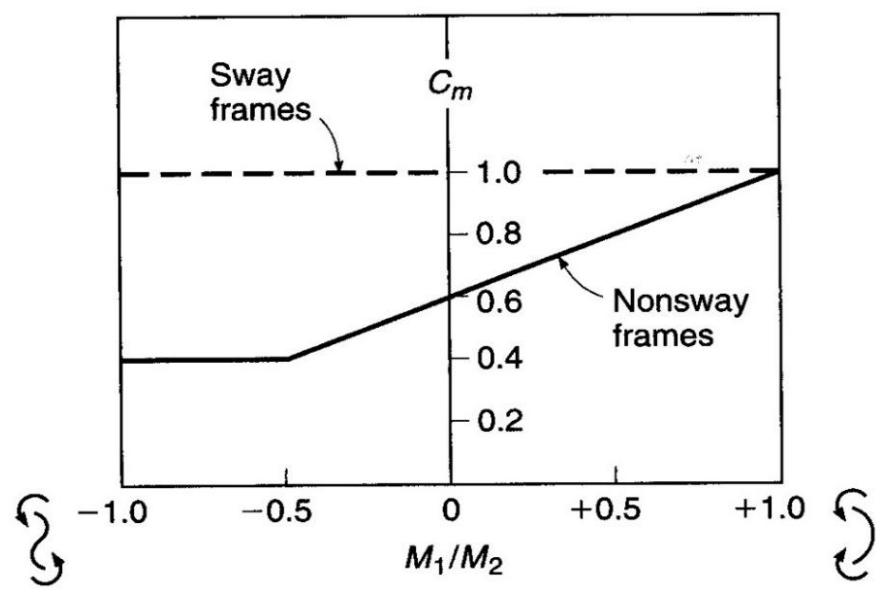

Fig. (2) Values of $\mathrm{Cm}$ for slender columns in sway and non-sway frames [9] 


\subsection{Magnifier factor $(\delta)$ :}

James K. W. and at al. (2012) [10] presented the slender column that have pin-ended support as shown in Fig. (3).The moments at the ends of the column under the action of the end moment Mo. The column deflects an amount $(\delta o)$. This will be referred to as the first-order deflection. When the axial loads $(\mathrm{P})$ are applied, the deflection increases by the amount $(\delta \mathrm{a})$. The final deflection at mid span is $(\delta=\delta o+\delta a)$. This total deflection will be referred to as the second-order deflection.

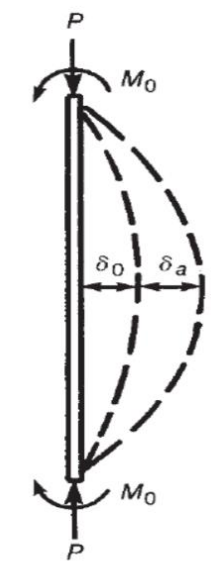

(a) Deflected

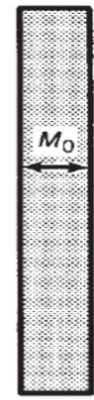

(b) $M_{0}$

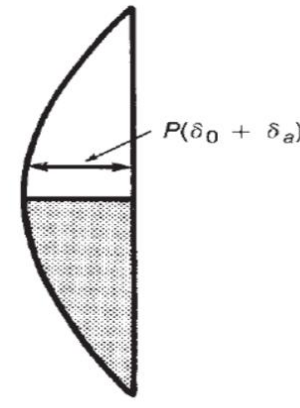

(c) P-S Moments.

Fig. (3) Moment and deflections [10]

For non-sway with unequal end moments the ACI code equation for magnified factor is

$$
\delta=C m / 1-(P u / 0.75 P c) \geq 1
$$

Where the value 0.75 term in Eq. (2) is stiffness reduction factor, designed to provide a conservative estimate of the critical load $P c$ which is given as:-

$$
P c=\frac{\pi^{2} E I}{\left(k l_{u}\right)^{2}}
$$

The above equation is according to ACI code eq. (10-13).

Where $k l_{u}=$ Effective length and $E I=$ flexural rigidity

The moment magnifier $\delta$ shall be calculated as

$$
\delta=\frac{1}{1-Q} \geq 1
$$

The above equation is according to ACI code eq. (10-20).

Where $Q$ is the stability Index for story. If $Q \leq 0.05$ the story is considered braced (nonsway). However, the story is considered unbraced (sway) if $Q>0.05$. Also Jostein $\mathrm{H}$. (2002\&2008) [4\&6] suggested the column or story are designated as braced or unbraced exclusively depending on their sensitivity to second order sides-way effects. For unbraced columns (sway) the magnifier is $\delta>1.05$ up to 1.10. Otherwise, braced (non-sway) the magnifier factor is $\delta \leq 1.05$.

\subsection{Column flexural rigidity (EI):}

The calculation of the critical load $P c$ in Eq. (3) involves the use of the flexural rigidity, EI, of the column section. The value of EI is chosen for a given column section and the effects of cracking, creep, and nonlinearity of the stress-strain curves at the time of failure. The ACI equation gives the following for the computation of EI in calculating the critical load of an individual column:

$$
E I=(0.4 \mathrm{Ec} I g) /(1+\beta d)
$$


The above equation is according to ACI code eq. (10-15).

Where $E_{c}=$ Modulus of elasticity of concrete, $I g=$ Moment of inertia of gross section and $\beta_{\mathrm{d}}=$ the ratio of the maximum factored axial dead load to the total factored axial load.

Note: used $E I=0.5 \mathrm{EcIg}$ according the assumptions for sections subjected to axial loads and bending moment in Egyptian codes ECP-203 [2]. However, the modulus of elasticity varies with different concrete strengths. The initial tangent is sometimes used to estimate the concrete modulus of elasticity, in which the slope of the stress-strain curve of concrete at the origin is evaluated. The Egyptian codes gives the following formula for estimating the concrete modulus of elasticity $E=4400 \sqrt{f_{c u}}$, Where $f c u$ is the concrete compressive strength in $\mathrm{N} / \mathrm{mm}^{2}$.

\subsection{Radius of gyration $(r)$ :}

The radius of gyration is a geometric property of a cross section that is used in the analysis and design of columns. According ACI code section 10.10.1.2. $r=0.3 \mathrm{~h}$ for a rectangular section and $r=0.25 h$ for a circular section, for other sections, $\mathrm{r}$ can be calculated from the area and moment of inertia of the gross concrete section as

$$
r=\sqrt{\frac{\mathrm{I}}{\mathrm{A}}}
$$

Where $\mathrm{I}=$ moment of inertia and $\mathrm{A}=$ cross-sectional area of the column.

From equations ( 1 to 5 ) the following equations could be obtained:-

$$
\begin{aligned}
& 1-\frac{\mathrm{Cm}}{\delta}=\frac{P u}{0.75 * \frac{\pi^{2} * 0.5 *\left(4400 \sqrt{f_{c u}}\right) * A r^{2}}{\left(k l_{u}\right)^{2}}} \\
& 1-\frac{\mathrm{Cm}}{\delta}=\frac{P u}{0.75 * \pi^{2} E I /\left(k l_{u}\right)^{2}}
\end{aligned}
$$

Where the slenderness $\lambda=\frac{\left(k l_{u}\right)}{r}$ the following is obtained:-

$$
\lambda=\left(1.63^{*} 10^{4} \sqrt{f_{c u}} *\left(1-\frac{\mathrm{Cm}}{\delta}\right) / \frac{\mathrm{Pu}}{\mathrm{A}}\right)^{0.5}
$$

The above Eq. (9) is a new formula which linked the concrete compressive strength $\left(f_{c u}\right)$ and stresses on column $(P u / A)$ with other factors.

\section{APPLICATION FOR PRACTICAL USE:}

The values of slenderness limits by Egyptian Code ECP-203 has been used as an example of application on the proposed new formula for estimating the values of parameter affecting the slenderness limits.

\subsection{Slenderness ratio in case of braced column (non-sway):}

Based on the previous results for braced columns the factors were taken as shown in table (1). However, the proposed new formula results are shown in in table (2) and figure (4). It can be seen that the slenderness limit which was adopted by the ECP-203 equal 30 is recognized at $\mathrm{Cm}=0.9$ and minimum stresses on column $P u / A=12 \mathrm{~N} / \mathrm{mm} 2$. 


\subsection{Slenderness ratio in case unbraced column (sway):}

Based on the previous results for unbraced columns the factors were taken shown in table (1). However, the proposed new formula results are shown in table (2) and figure (5). It can be seen that the slenderness limit which was adopted by the ECP-203 equal 23 is recognized at $\delta=1.08$ and minimum stresses on column $P u / A=11 \mathrm{~N} / \mathrm{mm} 2$.

Table (1) parameter affecting the slenderness limits in case of braced and unbraced columns.

\begin{tabular}{|c|c|c|c|c|}
\hline Cases & $\mathrm{Cm}$ & $\delta$ & $P u / A \mathrm{~N} / \mathrm{mm} 2$ & $f_{c u} \mathrm{~N} / \mathrm{mm} 2$ \\
\hline Braced (non- sway) & 0.40 to 1.00 & 1.05 & 10 to 40 & 20 to 45 \\
\hline Unbraced (sway) & 1.00 & 1.05 to 1.10 & 10 to 40 & 20 to 45 \\
\hline
\end{tabular}

Table (2) results of obtained parameter affecting the slenderness limits adopted by the ECP-203 in case braced and unbraced columns.

\begin{tabular}{|c|c|c|c|c|}
\hline Cases & $\mathrm{Cm}$ & $\delta$ & $P u / A \quad \mathrm{~N} / \mathrm{mm} 2$ & $f_{c u} \mathrm{~N} / \mathrm{mm} 2$ \\
\hline Braced (non- sway) & 0.90 & 1.05 & 12 & 22 \\
\hline Unbraced (sway) & 1.00 & 1.08 & 11 & 21 \\
\hline
\end{tabular}

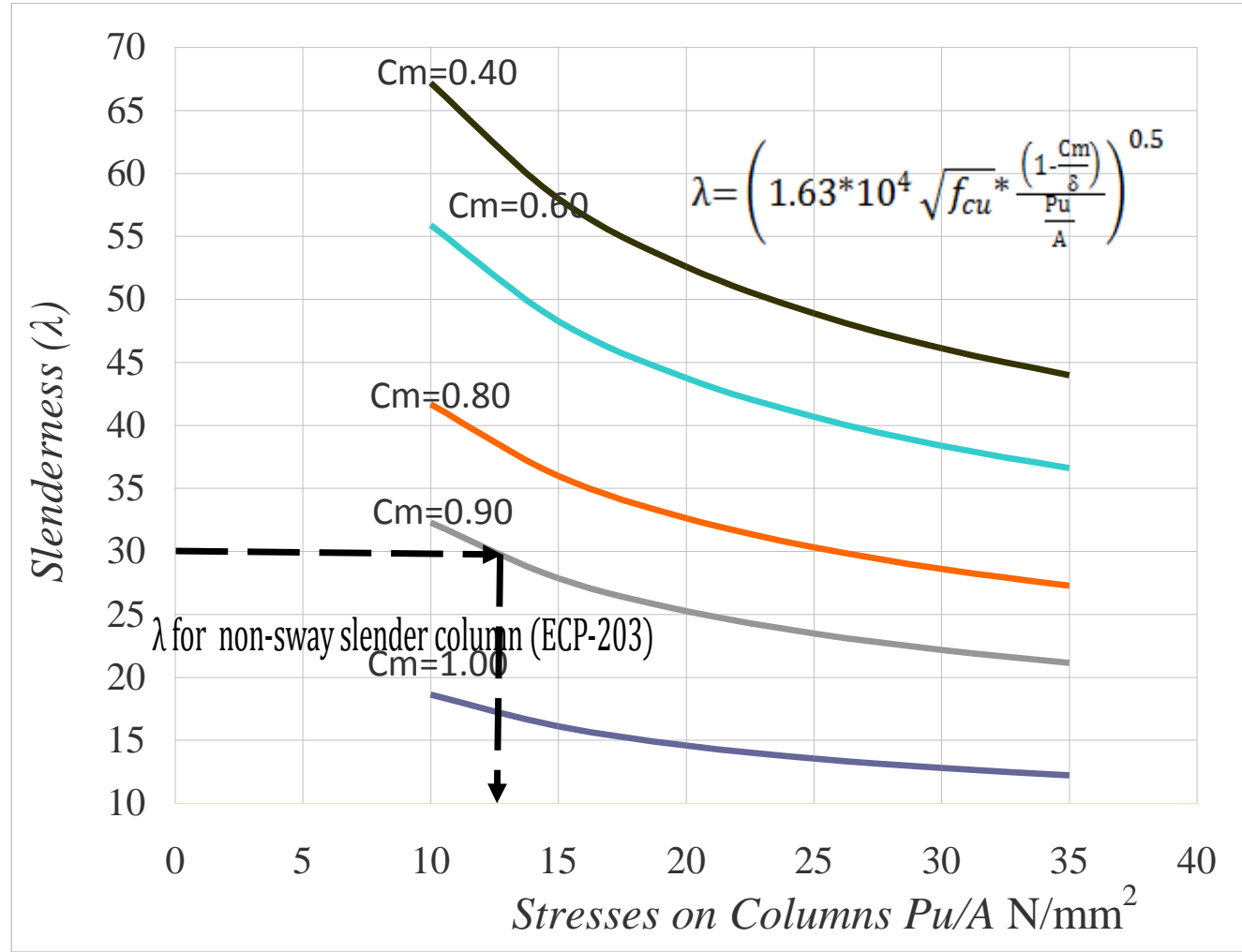

Fig. (4) Relationship between $(\mathrm{Pu} / \mathrm{A})$ and $(\mathrm{Cm})$ factor with slenderness rations in case braced column (non- sway) 


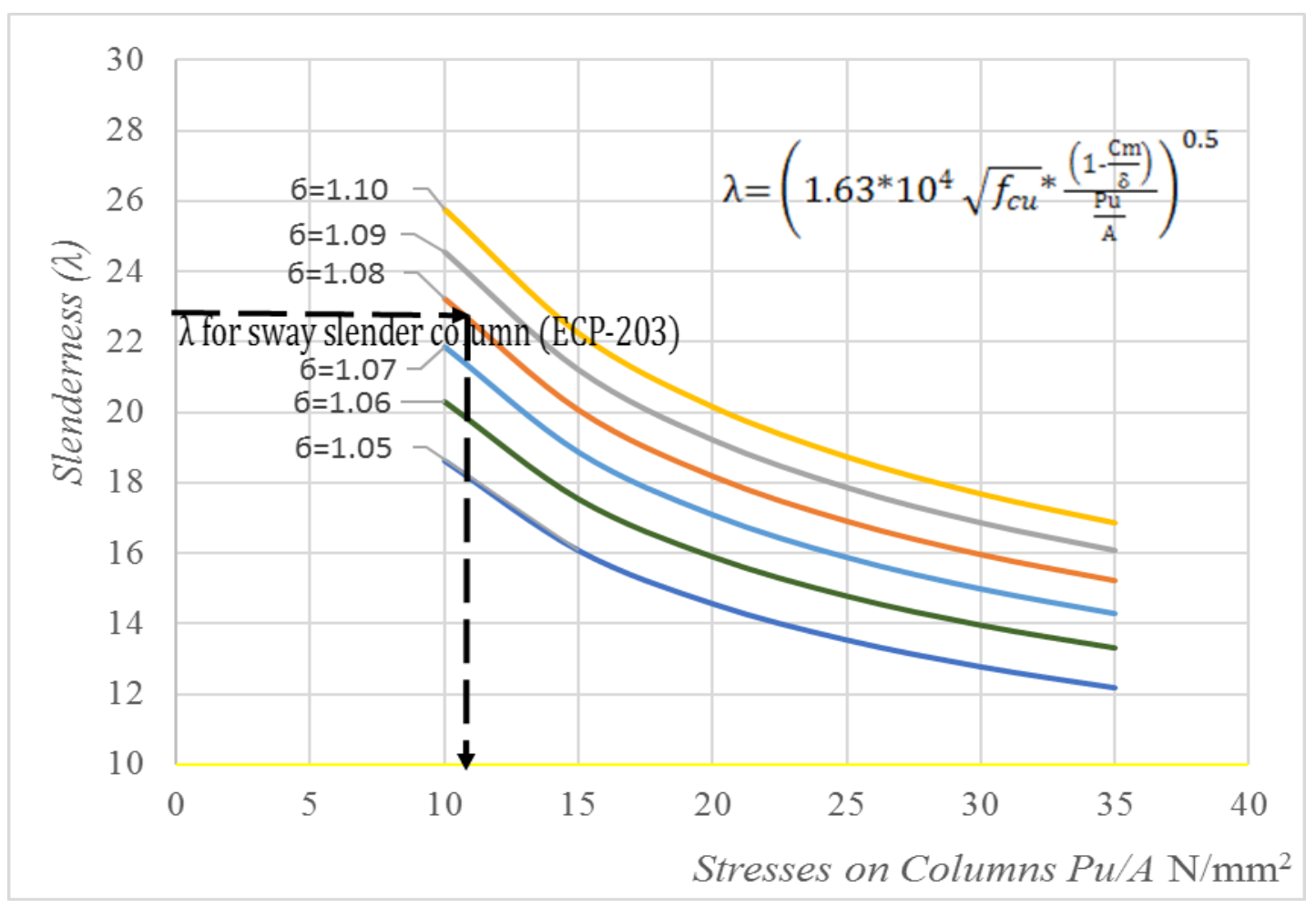

Fig. (5) Relationship between $(\mathrm{Pu} / \mathrm{A})$ and magnifier factor $(\mathrm{\delta})$ with slenderness rations in case unbraced column (sway)

\subsection{Simplified parameters for practical use:}

The most important parameters governing the behavior of slender concrete columns explicitly appear in the proposed new formula. To simplify the proposed new formula to be easy used in practical applications for braced column (non-sway) taking $\mathrm{Cm}=0.90, \delta=1.08$ and $f_{c u}=20$ to $45 \mathrm{~N} / \mathrm{mm}^{2}$ as shown in table (3) and figure (6). It can be seen that increase in compressive strength from 20 to $45 \mathrm{~N} / \mathrm{mm}^{2}$ with constant stresses on column the slenderness limits $(\lambda)$ increase from 32 to 40 with increase percentage $20 \%$.

Table (3) Effects of stresses on columns and concrete compressive strength on the slenderness limit of braced column (non-sway).

\begin{tabular}{|c|c|c|c|c|c|c|c|c|c|}
\hline \multirow{2}{*}{$\mathrm{Cm}$} & \multirow{2}{*}{$\delta$} & \multirow{2}{*}{$\begin{array}{c}\mathrm{F}_{\mathrm{cu}} \\
\left(\mathrm{N} / \mathrm{mm}^{2}\right)\end{array}$} & \multicolumn{7}{|c|}{$\mathrm{P}_{\mathrm{u}} / \mathrm{A}\left(\mathrm{N} / \mathrm{mm}^{2}\right)$} \\
\hline & & & 10 & 15 & 20 & 25 & 30 & 35 & 40 \\
\hline \multirow{6}{*}{0.9} & \multirow{6}{*}{1.05} & 20 & 32 & 26 & -- & -- & -- & -- & -- \\
\hline & & 25 & 34 & 28 & 24 & -- & -- & -- & -- \\
\hline & & 30 & 36 & 29 & 25 & 23 & -- & -- & -- \\
\hline & & 35 & 37 & 30 & 26 & 23 & 21 & -- & -- \\
\hline & & 40 & 38 & 31 & 27 & 24 & 22 & 21 & -- \\
\hline & & 45 & 40 & 32 & 28 & 25 & 23 & 21 & 20 \\
\hline
\end{tabular}




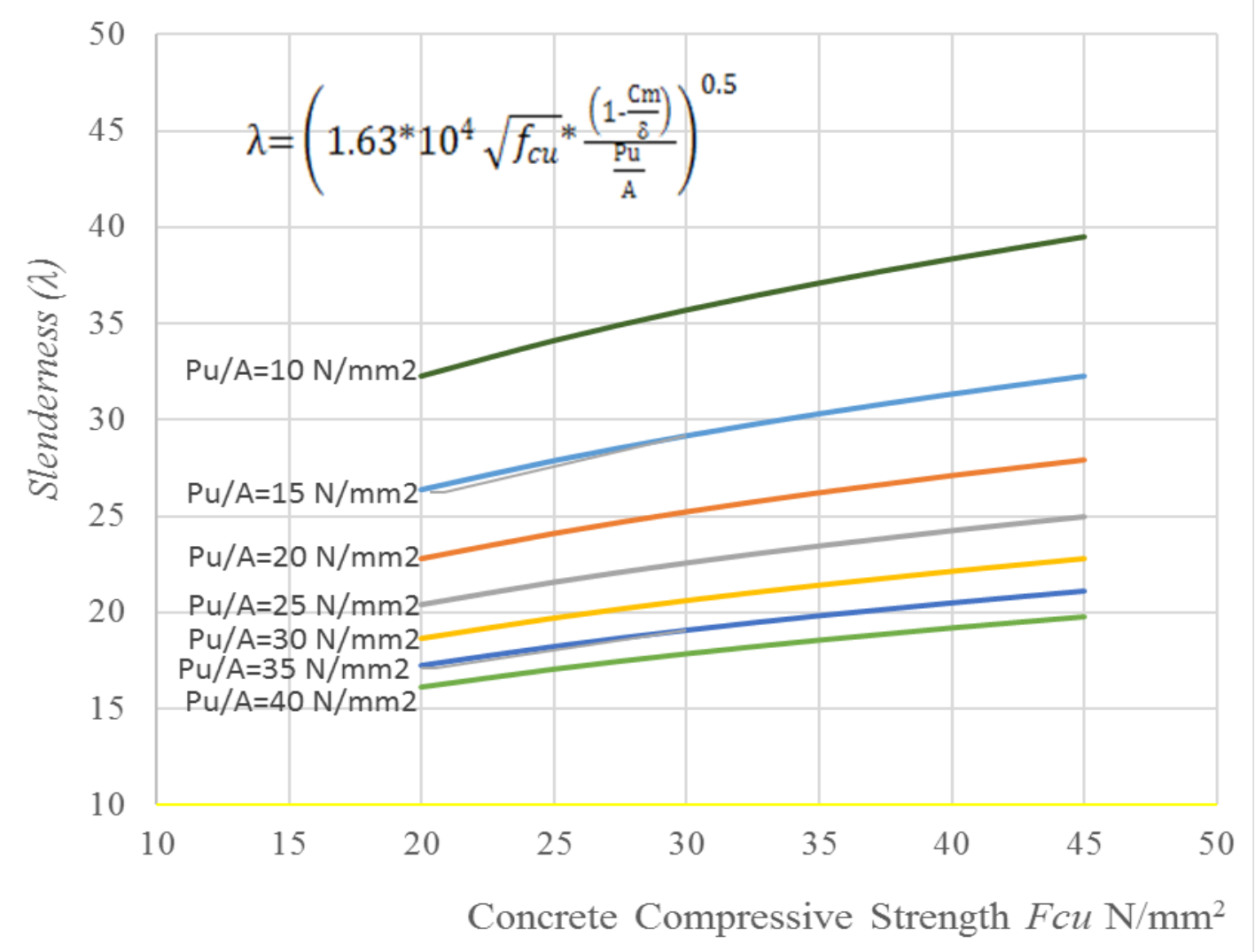

Fig. (6) Relationship between slenderness limit $(\lambda)$ and concrete compressive strength $\left(f_{c u}\right)$ In case braced column (non-sway)

Also, the proposed new formula to be used in practical applications for unbraced column (sway) taking that $\mathrm{Cm}=1.00, \delta=1.05$ and $f_{c u}=20$ up to $45 \mathrm{~N} / \mathrm{mm}^{2}$ as shown in table (4) and figure (7). It can be seen that the increase in compressive strength from 20 to $45 \mathrm{~N} / \mathrm{mm}^{2}$ with constant stresses on column, the slenderness limit $(\lambda)$ increase from 23 to 28 with increase percentage $17.8 \%$.

Table (4) Effects of stresses on columns and concrete compressive strength on the slenderness limit of unbraced column (sway).

\begin{tabular}{|c|c|c|c|c|c|c|c|c|c|}
\hline \multirow{2}{*}{$\mathrm{Cm}$} & \multirow{2}{*}{$\delta$} & \multirow{2}{*}{$\begin{array}{c}\mathrm{F}_{\mathrm{cu}} \\
\left(\mathrm{N} / \mathrm{mm}^{2}\right)\end{array}$} & \multicolumn{7}{|c|}{$\mathrm{P}_{\mathrm{u}} / \mathrm{A}\left(\mathrm{N} / \mathrm{mm}^{2}\right)$} \\
\hline & & & 10 & 15 & 20 & 25 & 30 & 35 & 40 \\
\hline \multirow{6}{*}{1} & \multirow{6}{*}{1.08} & 20 & 23 & 19 & -- & -- & -- & -- & -- \\
\hline & & 25 & 25 & 20 & 17 & -- & -- & -- & -- \\
\hline & & 30 & 26 & 21 & 18 & 16 & -- & -- & -- \\
\hline & & 35 & 27 & 22 & 19 & 17 & 15 & -- & -- \\
\hline & & 40 & 28 & 23 & 20 & 17 & 16 & 15 & -- \\
\hline & & 45 & 28 & 23 & 20 & 18 & 16 & 15 & 14 \\
\hline
\end{tabular}




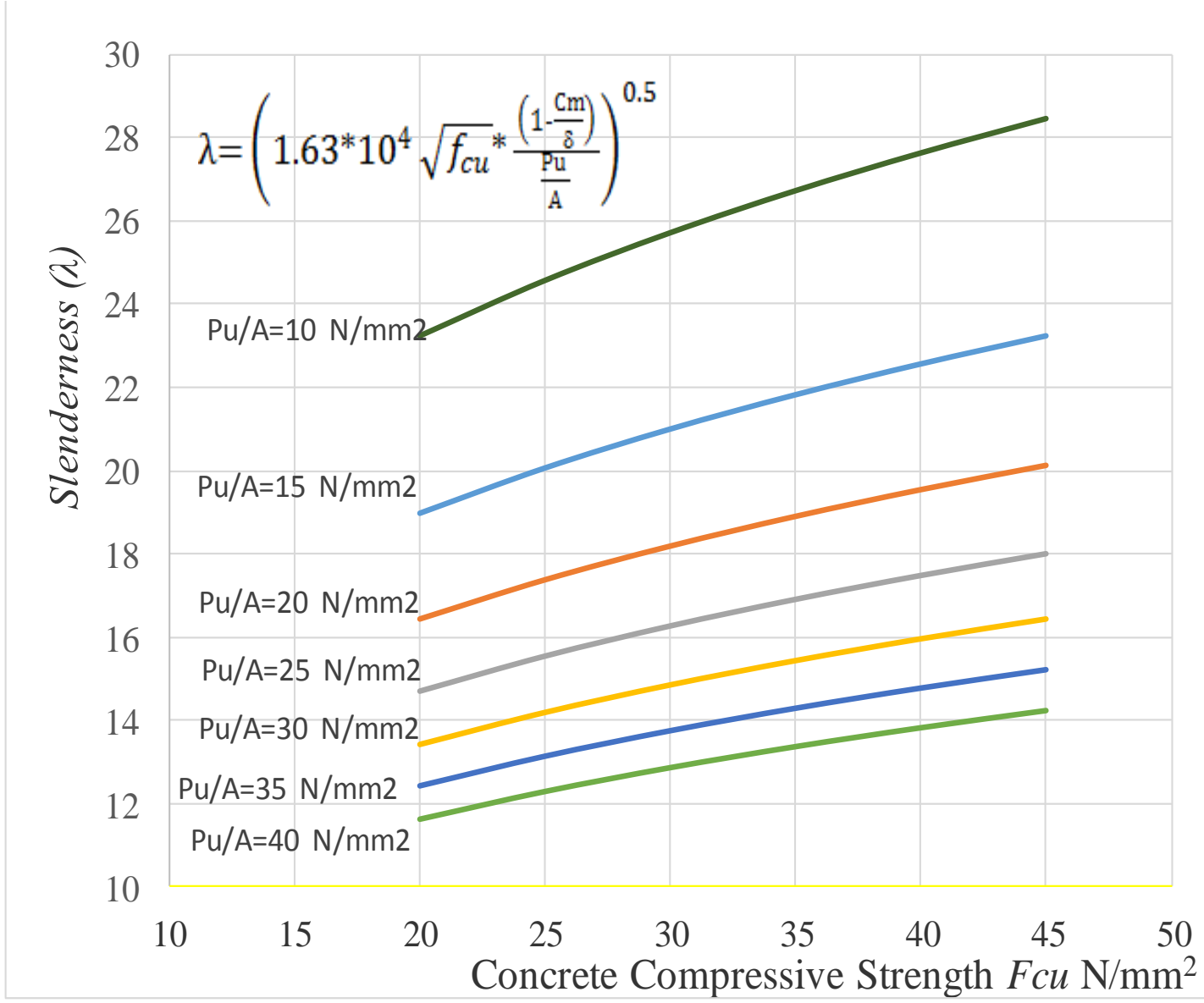

Fig. (7) Relationship between slenderness limit $(\lambda)$ and concrete compressive strength $\left(f_{c u}\right)$ In case unbraced column (sway).

To sum up, for practical use of the proposed new formula, first the designer must choose the concrete compressive strength $\left(f_{c u}\right)$ and calculate the column loads then suggested the concrete dimensions. After that the designer should determine the state of column (braced or unbraced).

Finally as shown in figures 6, 7 the new proposed formula (9) is a direct access to get the slenderness limits for braced and unbraced R.C. columns.

\section{CONCLUSIONS:}

In this research, some of the factors affecting the slenderness limits of reinforced concrete columns with pin ended have been evaluated. The most important factors affecting slenderness limits are the second order analysis, factor of equivalent uniform moment $(\mathrm{Cm})$, magnified factor $(\delta)$, flexural rigidity (EI) and concrete compressive strength (Fcu). However, the followings are concluded:

I. A new formula is proposed with associated graphs is easy to be used in determining slenderness limits for R. C. columns for pin ended support in cases of braced and unbraced columns.

II. Increasing the compressive concrete strength by about $55 \%$ increases the slenderness by limits about $20 \%$ in case of braced (non-sway).

III. Increasing the compressive concrete strength by about 55\% increase the slenderness by limits by about $17.8 \%$ in case of unbraced (sway).

IV. Increasing the stresses on columns decreases the slenderness limits.

V. Fair agreement has been obtained for application of slenderness limits values of ECP 203 code on the proposed new formula. 
Finally, it is suggested that codes of practices has to be revised for slenderness limits by taking into account the effect of compressive concrete strength and actual stresses on columns.

\section{REFERENCES}

[1] ACI Committee 318, "Building Code Requirements for Reinforced Concrete and Commentary ACI318M-11 and ACI 318RM-11", American Concrete Institute, Detroit, 2011.

[2] ECP 203"Egyptian Code of Practice for Designing and Construction of Reinforced Concrete Structures“, (2007).

[3] James G. Macgregor, John E. B., and Edward O. P. (1970)" Design of Slender Concrete Columns" ACI Journal I January 1970.

[4] Jostein Hellesland (2002)" Lower Slenderness Limit for Braced end-loaded R.C. Compression Members" Research Report in Mechanics, ISSN 0801-9940,November 2002.

[5] Mari A. R. and Jostein Hellesland (2005)" Lower Slenderness Limits for Rectangular Reinforced Concrete Columns" Journal of Structural Engineering ASCE, Vol. 131, No. 1, January, 2005.

[6] Jostein Hellesland (2008)" Mechanics and Slenderness Limits of Sway-Restricted Reinforced Concrete Columns" Journal of Structural Engineering ASCE, Vol. 134. No.8. August 2008.

[7] Ihsan A. S., Al-Sharrbaf Bassman R., Al-Bakri Bayan S. and Al-Nu man Kaiss F. S. (2008)" Factors Affecting the Slenderness Limit for RC Columns-The Use of the (ACI318M-05) Provisions" The $1_{\text {st }}$ Regional Conference of Eng. Sci. NUCEJ Spatial ISSUE vol.11,No.3, 2008 pp342-356.

[8] Bouzid T., Demagh K. (2010)" Practical Method For Analysis And Design Of Slender Reinforced Concrete Columns Subjected To Biaxial Bending And Axial Loads" Journal Slovak OF Civil Engineering, Vol. 2, May 2010.

[9] Nilson H., David D. and Charles W. Dolan (2010)" Design of Concrete Structures"14th Edition, published by McGraw-Hill companies, 2010.

[10] James K. Wight and James G. Macgregor (2012)" Reinforced Concrete Mechanics and Design" 6th Edition, published by Pearson Education, Inc., Upper Saddle River, New Jersey 07458, 2012. 